\title{
Pathology Study for Human Suicide
}

\author{
Da-Yong Lu*, Hong-Ying Wu and Bin Xu \\ School of Life Sciences, Shanghai University, Shanghai 200444, PR China
}

\begin{abstract}
Wide spectra of risk factors can generate human suicide episodes and victim. To achieve an ultimate goal of suicide management, pathological origin and progress of human suicide should be unveiled. Current different suicide origin and pathological progress between susceptible population, mental disordered patients and normal people should be understood. Therapeutic knowledge may be built by translating different types of pathology knowledge into clinically technical modernization (diagnostics and instruments).
\end{abstract}

\section{Introduction}

\section{Current situation}

There is a great amount of suicide events and mortality globally [13]. Nevertheless, pharmaceutical drugs and clinical managements may be improved by growing understanding of suicide origin and pathology at genetic and molecular levels. New diagnostic systems may promote the efficacy of suicide prediction, prevention and therapeutics in the future [4-5].

\section{Molecular diagnosis}

Wide spectra of clinical parameters (genetic, omics, synoptic, neural circuit and brain imaging) can be used to predict and treat human suicide. No biomedical convention has provided enough pathological information for suicide prediction. To achieve an ultimate goal of clinical suicide management, pathological origin and pathways should be identified by analyzing neuropsychiatric data and parameters between susceptible population and normal humans [6-8].

\section{Medical knowledge}

\section{Mood disorders}

There is a long history of knowledge and technical progresses in humans (suicide diagnosis and clinical therapy). These progresses look similarity but have great differences in pathological and therapeutic framework. If we carefully analyze different categories of potential suicide pathways, more sophisticate diagnostic techniques and relevant therapy will be created.

\section{Association and difference between suicide and mood disorder \\ In the first chapter, we describe the correlation between suicide and mood disorders in clinical symptoms [9]. However, there are also many other profiles, correlation, variability and characters between them.}

Like suicide, the epidemiological data of mood disorder is equally distributed (Table 1). It shows that female patients with mood disorder are more popular than their male counterparts. However, it shows that male suicide rates are usually higher than female suicide rates except China [4]. This mystery character is waiting for further validation. The underling causality for this unparallel rate needs to be discovered at
Table 1. Epidemiological statistics for mood disorders [7]

\begin{tabular}{|l|c|c|c|c|c|}
\hline & White & Irish & $\begin{array}{c}\text { Africa/ } \\
\text { Caribean }\end{array}$ & India & Pakistan \\
\hline Males & $2.7 \%$ & $5.8 \%$ & $5.6 \%$ & $2.5 \%$ & $3.8 \%$ \\
\hline Females & $4.8 \%$ & $6.8 \%$ & $6.4 \%$ & $3.2 \%$ & $2.9 \%$ \\
\hline
\end{tabular}

pathological levels. Are there any impulsive pathological mechanisms in suicide ideation and episodes? Today, there is no direct answer for it.

\section{Biological difference}

Human suicide events do not occur in all human population. It varies in age, gender, geographic and occupations [6]. Pathogenic progresses and stages may be sequential, cascade or reversible by drugs or other treatments. A wide variety of insiders (human genetic variation, plasma escalation for hormones and chemistry of different neural transmitters in humans) may determine human depressive conditions, suicide ideation and finally human mortality. It suggests that biological structure, function and chemistry are causative matter for many subsequent human suicide and mortality.

\section{Pathological pathways}

\section{Human psychiatric changes}

People nowadays see the suicide ideation and attempts by outside variables. They see less that genotypic or phenotypic alterations may also affect human suicide rates impacted outside pressure and consequence, especially in stochastic ways in the clinic. A heat wave of genetic and molecular associations between psychiatric symptoms and suicide behaviors is a future trend. Genetic study for mental disorders is just emerged over the past decade due to technical advances, such as next-generation clinical psychiatric or suicide risk prediction and

${ }^{\star}$ Correspondence to: Da-Yong Lu, School of Life Sciences, Shanghai University, Shanghai 200444, PR China, E-mail: ludayong@shu.edu.cn

Key words: human suicide, neuropsychiatric diagnosis, cerebral image, brain density, pathology

Received: February 20, 2021; Accepted: March 08, 2021; Published: March 11, 2021 
prevention in neuroscience (gradual maturity in modern diagnosis and prognosis). In order to keep this momentum, proposed pathological progresses are suggested in Table 2.

\section{Disease progress in background density.}

This "outside-to-insider modality" can impact medical landscape in the clinic in the future. It should be very useful in the clinic if it is the truth. It is technically and theoretically unfinished now. Yet ethically issue is still one of the biomedical challenge now (lacking non-invasive technology in the hospitals). Maybe we should wait for more time to embrace new techniques, smart animal models, computational analysis and clinical diagnostics in wider-range.

\section{Knowledge gaps}

Diagnostic comparison between suicide risks and mood disorder is a modern challenge. Yet, the modern biomedical diagnostics (genetics variation, synaptic abnormal, neural circuitry and brain image) improves in accelerate speed. Mental disorder (especially mood disorders) is an excellent vehicle to promote clinical researches for human suicide [2,9-12]. Following details may be noted;

Mental disorders are classified into several dimensions. Most of which are associated with higher suicide events, episodes and mortality. Different suicide risks (symptoms or neural-oriented) are associated with higher suicide rates, behavior and mortality. The knowledge gap (similarity and diversity between suicide symptoms and biologicalvariation should be filling in the future (Table 3 ).

The different pathological knowledge may come from disease domain generalizing.

\section{Immune system damages}

Human immune system damages are associated with human depression and mental disorders. The evaluation of human immunity may be useful for suicide prediction and treatments. This topic and knowledge develop is an emerging discipline for human depression and suicide treatment. More study is indispensable.

Table 2. Proposed pathological evolutional mechanisms of certain kinds of human suicide

\begin{tabular}{|c|c|c|}
\hline \multicolumn{2}{|c|}{ Pathological progress of human suicides } & \multirow{2}{*}{\begin{tabular}{|l|} 
Treatment \\
Alleviation measures
\end{tabular}} \\
\hline Outside pressure & Traumatic injury & \\
\hline \multicolumn{2}{|c|}{ Unpleasant feelings } & Psychological intervention \\
\hline \multicolumn{2}{|c|}{ Depressive symptoms } & Modern diagnosis and treatments \\
\hline \multicolumn{2}{|c|}{ Neural biological dysfunction } & Technical intervention \\
\hline \multicolumn{2}{|c|}{ Psychiatric diseases } & Drugs or others \\
\hline
\end{tabular}

Table 3. Central nerve system characters

\begin{tabular}{|l|l|}
\hline Types & Symptoms \\
\hline Sleeps & Abnormal dreams \\
& Difficult sleep (insomnia) \\
Somnolence \\
\hline Fatigue \\
\hline Psychiatric symptoms & Irritability \\
& Nervousness \\
& Memory loss \\
Dizziness \\
\hline Emotional & Impaired concentration \\
\hline & Mood change \\
& Sadness \\
\hline Hyperhidrosis \\
Euphosia \\
\hline
\end{tabular}

\section{Inflammatory machinery}

Serious human depression may combine with human brain, gastrointestinal symptoms and inflammatory hormone escalation. Some anti-inflammatory agents, drugs or herbs, such as minuomeisu are reported to manage human mental health and suicide in previous reports [13].

\section{Gut-brain axis}

The latest discovery suggests that human mental health problem is not restricted in human brain. Human gastrointestinal systems play key roles for human mental health and sleep problem. Some microbial regulatory or food consuming (vegetable fibers or antibiotics) may be associated with suicide behaviors [14-15]. This is an important area for further investigation in human mental study.

\section{Drug utility}

Overdosing of therapeutic drugs may induce human suicide and many other types of undesired side-effects [16-23]. The therapeutic relationship between drug-induced suicidal ideation and human genetic variation, (especially single nucleotide polymorphism, SNP) has been especially interesting [16-23]. This kind of genetic variation is especially targeted to metabolizing enzymes (CYP2D6 and others) other than that of brain functional molecules. The drug metabolizing enzymes can alter drug level in human blood and drug administration interval (absorption, distribution, metabolizing, excretion and toxicity, ADMET).

\section{Clinical diagnosis}

\section{Pharmacogenomics}

In clinical PG diagnosis, the pathophysiologic molecules and pathways are less common than polymorphism of metabolizing enzymes. Since there is a strong relationship between drug blood concentration, therapeutic efficacies and side effects, monitoring therapeutic efficacies and toxicities of many psychiatric drugs is very important and needs to shed new light. Drug-toxic molecules and drug-targeted molecules are proposed to be different mechanisms.

\section{Pathology diagnosis}

To update modern diagnosis for human suicide, understanding the pathological processes and network is indispensable. It provides pathotherapeutic information of human suicide. The best genetic or molecular candidates for drug therapy prediction are new frontiers in suicide study and have great biomedical significance and impacts. Genetic panels affecting both drug-active and drug-toxic genes (molecules) might be indispensable avenues for in-depth scientific investigations of patient's suicides and self-injure [20-22]. New technique invention for clinical suicidal diagnostics is very useful. It may increase the specificity and reduce therapeutic costs.

\section{Image-based diagnosis}

Apart from genetic or molecular diagnosis, brain or cerebral atrophy or change [24-28] and human facial image is a hotspot in mental health treatment study. Yet, it is at a primitive stage. Human facial image and eye movement rates are useful parameters for human cognitive/behavior damage and neurodegenerative diseases (Alzheimer and Parkinson diseases). Would this type of image diagnosis be useful in human suicide prediction? It may contain individual cerebral 
structure variations or software imperfections. As a result, further scientific investigating relationship and knowledge gaps between visual changes and genetic/molecular variations are needed.

\section{Future directions}

\section{Overview}

Associations between "suicide pathology" and modern diagnosis are important for modern suicide medication. Following pathways may be useful for clinical trials. To understand that, headlines are promoted;

\section{Previous hypotheses}

- Identifying relationships between environmental stress and human personality.

- Genome-wide associate study (GWAS) between patients and normal people [29-35].

- Algorithm, stochastic, algebra, statistics comparisons of human suicide (risks, evidence and mortality).

\section{New ideas, mechanisms and technologies}

- Finding out genetic/molecular/visual-based diagnostics [16-17]

- Modern animal models such as genetic-knocked out, opto-genetics, bioinformatics, genetic engineering mice (GEM), genomic editing and others may be integrated into suicide study [36-41].

- Genetic study of repeated DNA for diagnosis, new drug discoveries and clinical therapeutics

- Invitation of more mathematics or physics major students and scholars in suicide investigation.

In the future, growing attentions should be paid on suicide diagnostics and therapeutic choices, especially on the relationship between chemical, genetic, molecular, environmental and social factors for therapeutic outcomes. We look forward to scientific promotions on personalized medicine [42].

\section{Conclusion}

Suicidal episodes are determined by etiology (environmental variables) and human personality (genetics and past training). We look forward to a new suicide landscape in the future.

\section{References}

1. Cao S, Lu DY, Lu TR, Yarla NS (2017) Different disciplines in the field of suicide study. Novel Approach Drug Design \& Develop 1: 555568

2. Lu DY (2017) Suicide Risks and Treatments, New Ideas and Future Perspectives. Ed Da-Yong Lu, Nova Science Publishers, New York.

3. Lu DY, Lu TR, Zhu PP, Che JY (2016) The efficacies and toxicities of antidepressant drugs in clinics, building the relationship between Chemo-Genetics and SocioEnvironments. Cent Nerv Syst Agents Med Chem 16: 12-18 [Crossref]

4. Bondy B, Buettner A, Zill P (2006) Genetics of suicide. Mol Psychiatry 11: 336-351 [Crossref]

5. Lu DY, Lu TR, Yarla NS, Wu HY (2017) Genetics in suicide treatments, modern diagnosis establishments. J Mental Disorders \& Treatment 3: 145.

6. Lu DY, Wu HY, Cao S, Che JY (2020) Historical analysis of suicide. J Translational Genetics \& Genomics 4: 33.

7. Davison K (2006) Historical aspects of mood disorders. Psychiatry 5: 115-118.

8. Marneros A (2009) Mood disorders: epidemiology and natural history. Psychiatry 8: $52-55$.
9. Lu DY, Zhu PP, Wu HY, Yarla NS, Zhu H, et al. (2016) Human suicide study, is there an associations between suicide and mental illness? Metabolomics 6: 186.

10. Serafini G, Salano P, Amore M (2015) Suicidal ideation: a comprehensive overview. Suicidal Ideation: Predictors, Prevalence and Prevention. Bradley Weaver (Ed), Nova Science Publishing, US pp: 1-42.

11. Kerfoot M (2009) Managing suicidal behavior in adolescents. Psychiatry 8: 252-256.

12. Lilley R, Owens D (2009) Services for assessment, after care, and psychological treatment following self-harm. Psychiatry 8: 246-251.

13. Sharon G, Sampson TR, Geschwind DR, Maznanian SX (2013) The central nerve system interaction in inflammatory bowel diseases. Gastroenterology 144: 36-49. [Crossref]

14. Bonaz BL, Bernstein CN (2016) Brain-gut and the gut microbiome. Cell 167: 915-932 [Crossref]

15. Mohajeri MH, La Fata G, Steinert RE (2018) We begin relationship between the gutmicrobiome and brain function. Nutrition Rev 76: 481-496. [Crossref]

16. Malhotra D, Sebat J (2012) CNVs: harbingers of a rare variant revolution in psychiatric genetics. Cell 148: 1223-1241. [Crossref]

17. Krystal JH, State MW (2015) Psychiatric disorders: diagnosis to therapy. Cell 157 201-214 [Crossref]

18. Menchetti, M, Bortolotti, B, Rucci, P, Scocco, P, Bombi, et al. (2010) Depression in primary care: Interpersonal counseling vs selective serotonin reuptake inhibitors. The DEPICS study. A multicenter randomized controlled trial. Rationale and design. BMC Psychiatry 10: 97. [Crossref]

19. Menchetti, M, Rucci, P, Bortolotti, B, Bombi, A, Scocco, P, et al. (2014) Moderator of remission with interpersonal counseling or drug treatment in primary care patients with depression: randomized controlled trial. Br J Psychiatry 204: 144-150. [Crossref]

20. Brent D, Melhem N, Turecki G (2010) Pharmacogenomics of suicidal events. Pharmacogenomics 11: 793-807. [Crossref]

21. Lu DY, Lu TR, Zhu PP (2012) Genetics in neural toxicities of drugs. Cent Nerv Syst Agent Med Chem 12: 250-253. [Crossref]

22. Lu DY, Lu TR, Zhu PP (2013) Pharmacogenetics in neural toxicities of drugs. Pharmacogenomics 14: 1129-1131.

23. Lu DY, Lu TR, Zhu PP, Che JY (2015) Genetics and bioinformatics study of antidepressant drugs, recent advancements and future trends. Suicidal Ideation: Predictors, Prevalence and Prevention. Weaver B (Ed) Nova Science Publishing, US.

24. Frangou S (2009) Brain structural changes in mood disorders. Psychiatry 8: 105-106.

25. Roiser JP, Rubinsztein JS, Sahakian BJ (2009) Neuropsychology of affective disorders. Frangou S. Brain structural changes in mood disorders. Psychiatry 8: 91-96.

26. Desmyter S, Bijttebier S, Heeringen KV (2013) The role of neuroimaging in our understanding of the suicidal brain. CNS Neurol Disord Drug Targets 12: 921-929 [Crossref]

27. Frangou S (2017) Functional neuroimaging in mood disorder. Psychiatry 6: 102-104.

28. Miller G (2016) Brain scans, a prone to false positive study says. Science 353: 209-209.

29. Laje G, Allen AS, Akula N, Manji H, Rush AJ, et al. (2009) Genome-wide association study of suicidal ideation emerging during citalopram treatment of depressed outpatients. Pharmacogenet Genomics 19: 666-674 [Crossref]

30. Garriock HA, Kraft JB, Shyn SI, Peters EJ, Yokoyama JS, et al. (2010) A genome wide association study of citalopram response in major depressive disorder. Biol Psychiatry 67: 133-138 [Crossref]

31. Uher R, Perroud N, Ng MY, Hauser J, Henigsberg N, et al. (2010) Genome-wide pharmacogenetics of antidepressant response in the GENDEP project. Am J Psychiatry 167: 555-564. [Crossref]

32. Lu DY, Lu TR, Che JY, Zhu PP (2014) Genetics and bioinformatics studies of antidepressant drug therapeutic efficacies and toxicities, a current overview. Recent Pat CNS Drug Discov 9: 193-199.

33. Zhao Y, Xiong N, Liu Y, Zhou YH, Li NM, et al. (2013) Human dopamine transporter gene: differential regulation of 18-kb haplotypes. Pharmacogenomics 14: 1481-1494 [Crossref]

34. Youngtrom IA, Strowbridge BW (2012) Visual landmarks facilitate rodent, spatial navigation in virtual reality environment. Learn Mem 9: 84-90. [Crossref] 
35. Menke A, Samann P, Kloiber S, Czamara D, Lucae S, et al. (2012) Polymorphisms within the metabotropic glutamate receptor 1 gene are associated with depression phenotypes. Psychneuroendocrinology 37: 565-575

36. Reardon S (2015) Brain study seeks roots of suicide. Nature 528: 19. [Crossref]

37. Sanchez A, Salvader M, Figneroa C, Guerrero RC, Hurtaclo LP, et al. (2013) Impact of pharmacogenetics on CNS side effects related to efavirenz. Pharmacogenomics 14: 1167-1178. [Crossref]

38. Lindquist M (2020) Neuroimaging results altered by varying analysis pipelines. Nature 582: 36-37. [Crossref]
39. Nature Neuroscience (2020) Depressive-like behaviours in mice caused by night-time light exposure. Nat Neuroscience.

40. Jiang JJ, Yan ZZ, Sheng C, Wang M, Guan QL, et al. (2019) A novel detection tool for mild cognitive impairment patients based on eye movement and electroencephalogram. J Alzheimer's disease 72: 389-399 [Crossref]

41. Reddy VP, Aryal P, Robinson S, Rafiu R, Obrenovich M, et al. (2020) Polyphenols's in Alzheimer's disease and in the gut-brain axis. Microorganisms 8: 199 [Crossref]

42. Lu DY, Wu HY, Lu TR (2020) Human suicide study, new insights and drug development. J Community Medicine 3: 1028.

Copyright: (C2021 Da-Yong Lu. This is an open-access article distributed under the terms of the Creative Commons Attribution License, which permits unrestricted use, distribution, and reproduction in any medium, provided the original author and source are credited. 